\title{
GHTD-amide: A naturally occurring beta cell-derived peptide with hypoglycemic activity
}

\author{
S.G. Paule ${ }^{a, 1}$, B. Nikolovski ${ }^{a, 1}$, R.E. Gray ${ }^{a}$, J.P. Ludeman ${ }^{a}$, A. Freemantle ${ }^{a}$, \\ R.A. Spark ${ }^{\text {a }}$, J.B. Kerr ${ }^{\text {b }}$, F.M. Ng ${ }^{\text {a }}$, P.Z. Zimmet ${ }^{\mathrm{a}, \mathrm{c}}$, M.A. Myers ${ }^{\mathrm{a}, 2, *}$ \\ ${ }^{a}$ Department of Biochemistry and Molecular Biology, Monash University, Wellington Road, Clayton, Victoria 3800, Australia \\ ${ }^{\mathrm{b}}$ Department of Anatomy and Cell Biology, Monash University, Clayton, Victoria 3800, Australia \\ ${ }^{\mathrm{c}}$ Baker IDI Heart and Diabetes Institute, Caulfield, Victoria 3162, Australia
}

\section{Introduction}

Regulation of blood glucose primarily revolves around control of insulin secretion and action. In addition to insulin, beta cells produce a variety of bioactive peptides including amylin, pancreastatin, preptin, and kisspeptins. Amylin contributes to metabolic regulation through its actions on insulin secretion and insulin sensitivity $[6,13]$, and feedback signals to the brain that reduce food intake [25]. Pancreastatin, the product of a proteolytic cleavage of chromogranin-A unique to beta cells [26,29], and

\footnotetext{
* Corresponding author. Tel.: +613 53279291; fax: +61353279240.

E-mail address: m.myers@ballarat.edu.au (M.A. Myers).

1 They contributed equally to the manuscript.

2 Current address: School of Science and Engineering, University of Ballarat, Ballarat, Victoria 3353, Australia.

Abbreviations: BLAST, basic local alignment and search tool; ES, electrospray; FBG, fasting blood glucose; GHTD-amide, alpha amidated tetrapeptide with the sequence Gly-His-Thr-Asp; MALDI, matrix assisted laser desorption ionization; PDA, photodiode array; PMF, peptide mass fingerprint; TFA, trifluoroacetic acid; TOF, time of flight.
}

kisspeptins [21], both reduce glucose stimulated insulin release $[11,21]$, whereas preptin, a cleavage product of proinsulin-like growth factor II, appears to amplify glucose stimulated insulin secretion [4]. Pancreatic peptides that originate from other cells types but also influence insulin secretion include Ghrelin, which is predominantly expressed in the gut mucosa but also found in islet alpha cells [8] and galanin, which is expressed in nerve endings surrounding the islets [28]. Both of these peptides inhibit insulin secretion $[10,28,1,27]$. Comprehensive knowledge of all factors controlling insulin secretion and action is required to complete our understanding of glucose homeostasis and its disturbance in disease states.

In the early 1970 s a peptide containing preparation with insulin potentiating activity was isolated from human urine [19,32] but the active constituent remained chemically unidentified. Based on chromatographic properties and activity the urinary peptide was originally thought to be a fragment of growth hormone called acceleratory fragment of growth hormone or AcG that derived from pituitary extracts $[19,20]$. Improvements in liquid chromatography and mass spectrometry have now allowed the purification to near homogeneity of this peptide from the original semi-pure prepara- 
tion. Here we show that the urinary peptide is unrelated to growth hormone and has the sequence Gly-His-Thr-Asp-amide (GHTDamide) that synthetic GHTD-amide promotes storage of glucose as glycogen and we provide evidence that endogenous GHTD-amide is produced by pancreatic beta cells.

\section{Methods}

\subsection{Peptide purification and identification}

Partial purification of peptide from urine was performed as described previously [20]. The lyophilized material was dissolved in $0.1 \%$ trifluoroacetic acid (TFA) and purified to near homogeneity by reverse phase HPLC chromatography on C18 and C3 columns. First, partially purified urinary peptide was eluted isocratically for 5 min followed by a linear gradient of $50 \%$ acetonitrile on a Vydec C18 column. Bioactive fractions were identified by measuring the incorporation of ${ }^{14} \mathrm{C}$-glucose into glycogen in rat hemidiaphragm. Active fractions were pooled and further purified using a Vydac $\mathrm{C} 3$ column by isocratic elution in $5 \%$ acetonitrile, $1 \%$ TFA. This step was repeated a further 2 times, with bioactive fractions pooled, lyophilized and redissolved in 0.1\% TFA after each step and then reapplied to the column. N-terminal sequence analysis was performed on an ASI 477 "pulse liquid" protein sequencer with an on-line ABI 120 A analyzer (Applied Biosystems, Inc. Model 475 A). The ES-MS and MS/MS measurements were performed on a micromass platform instrument.

\subsection{Animal experiments}

GHTD-amide was synthesized by standard solid phase Fmoc chemistry (Mimotopes, Melbourne, Australia). Male Wistar rats were from the Monash Animal Services facility and all procedures conformed to the NIH principles of laboratory animal care and were approved by the Monash University Animal Ethics Committee. Rats were given free access to food and water prior to overnight fasting. Male Wistar rats 6-8 weeks of age were fasted then injected intravenously in the tail vein with $60 \mathrm{mg} / \mathrm{kg}$ streptozotocin (stz). Rats with fasting blood glucose (FBG) concentrations greater than $11 \mathrm{mM} 5$ days after stz injection were included in the next stage of the experiment. Insulin deficiency was confirmed by RIA measurement of rat serum insulin (Linco, Millipore Biosciences, Australia).

Insulin-deficient rats were treated with GHTD-amide and/or insulin in a cross-over study. Rats $(n=7)$ were randomized into 2 treatment groups and received by intraperitoneal injection either $1 \mathrm{Unit} / \mathrm{kg}$ insulin (bovine insulin, Sigma) followed 2 days later by $1 \mathrm{U} / \mathrm{kg}$ insulin plus $4.27 \mathrm{mg} / \mathrm{kg}$ GHTD-amide or vice versa. The order of treatment had no effect on the experimental outcomes and the FBGs prior to each treatment were similar $(16.5 \pm 1.7 \mathrm{mM}$ versus $17.3 \pm 1.4 \mathrm{mM}$, mean $\pm \mathrm{SEM}, n=7$ ). After injection, blood glucose was measured at regular time intervals over $2 \mathrm{~h}$.

\subsection{Glycogen synthesis}

Glycogen synthesis was measured in HepG2 human hepatoma cells and $\mathrm{C} 2 \mathrm{C} 12$ rat myotubes. Cells were maintained at $37^{\circ} \mathrm{C}, 5 \%$ $\mathrm{CO}_{2}$ in Dulbecco's modified Eagle medium (Gibco BRL) and 10\% fetal bovine serum. C2C12 myoblasts were differentiated post confluence to myotubes by culturing in 5\% horse serum for 3-4 days. Cells were serum starved overnight in media containing $5.5 \mathrm{mM}$ glucose. The media was aspirated and replaced with fresh media supplemented with $0.4 \mu \mathrm{Ci} / \mathrm{ml} \mathrm{D}-\left[\mathrm{U}^{-14} \mathrm{C}\right]$ glucose and containing insulin or GHTD-amide at the required concentrations. After incubation at $37^{\circ} \mathrm{C}$ for $2 \mathrm{~h}$ the medium was removed and the cells were washed with ice-cold phosphate-buffered saline and harvested. Glycogen was extracted according to the method of Huang et al. [14]. The radioactivity incorporated into glycogen was then measured by scintillation counting. Activity was corrected for protein content and the results expressed as the percentage of activity compared to the basal rate of incorporation.

\subsection{Peptide detection in MIN6 cell culture}

MIN6 cells were cultured at $37^{\circ} \mathrm{C}, 5 \% \mathrm{CO}_{2}$ in DMEM with $10 \%$ FCS. For analysis of peptide secretion, a near confluent layer of cells was washed then incubated in serum free media for $24 \mathrm{~h}$.

GHTD-amide in cell culture media was detected by reverse phase-HPLC chromatography with a Photo Diode Array (PDA) equipped Shimadzu 10A-VP system. Samples were centrifuged at $13,000 \times g$ for $5 \mathrm{~min}$ before loading onto Phenomenex Luna(2), 10.0 or $4.6 \mathrm{~mm}$ i.d. $\times 250 \mathrm{~mm} \mathrm{C18}$ columns that had been equilibrated with $10 \%$ buffer B $(90 \%$ acetonitrile, $0.1 \%, \mathrm{v} / \mathrm{v}$, $\mathrm{H}_{3} \mathrm{PO}_{4}, 2.5 \mathrm{mM}$ octane sulfonic acid), at 2.5 (10.0 mm i.d.) or 1.0 (4.6 $\mathrm{mm}$ i.d.) $\mathrm{ml} / \mathrm{min}$. After sample injection buffer B was increased over a linear gradient of buffer A (milliQ water with $0.1 \%, \mathrm{v} / \mathrm{v}$, $\mathrm{H}_{3} \mathrm{PO}_{4}$ and $2.5 \mathrm{mM}$ octane sulfonic acid) to $100 \%$ over $25 \mathrm{~min}$. The retention times of synthetic GHTD-amide were $16.89(10.0 \mathrm{~mm}$ i.d.) or 16.29 (4.6 mm i.d.) minutes and a standard curve using known amounts of GHTD-amide was established for quantification of unknown amounts of peptide. PDA spectra and Matrix Assisted Laser Desorption Time Of Flight Mass Spectrometry (MALDI-TOF) were used to verify the molecular weight and peptide composition of the putative GHTD-amide in samples. MALDI-TOF and MALDIpeptide mass fingerprint (PMF) spectra were acquired using an Applied Biosystems 4700 MALDI-TOF/TOF mass spectrometer; data were analyzed using GPS explorer software.

\subsection{Antibodies, radioimmunoassay and immunofluorescence}

GHTD-amide conjugated to diphtheria toxoid via an amino terminal cysteine residue was used to immunize rabbits and mice (Institute of Medical and Veterinary Science, Adelaide, Australia). Serum was collected after primary inoculation and 3 booster injections.

An analogue of GHTD-amide containing a tyrosine $(\mathrm{Y})$ at the amino terminus (YGHTD-amide) was labeled with Sodium ${ }^{125}$ Iodide (Amersham) by chloramine-T oxidation. Labeled peptide was separated from unbound label using Sep-Pak C18 cartridges. Between 30 and 50,000 cpm of ${ }^{125}$ I-YGHTD-amide per tube was mixed with rabbit anti-sera raised to GHTD-amide, the sample containing competing peptide and a buffer containing fish skin gelatin. After equilibration overnight at $4{ }^{\circ} \mathrm{C}$ the immune complexes were precipitated with a precipitating system for immune complexes (Linco, Millipore Biosciences, Australia) and centrifugation and the amount of ${ }^{125} \mathrm{I}$ in the precipitate was measured. Peptide analogues for competition were synthesized by standard methods (GL Biochem, Shanghai, China).

Indirect immunofluorescence was performed on formalin fixed, paraffin embedded tissue sections. Mouse tissue sections were cut to a thickness of $5 \mu \mathrm{m}$ and mounted on a positively charged glass slides. A panel of human endocrine tissues was purchased from Abcam Ltd., Cambridge, UK. Tissues included were adrenal, maxillary gland, thyroid (fetal), brain (pituitary gland), parathyroid and pancreas. Antibodies were guinea pig anti-insulin (Dako), antiGHTD-amide, rabbit anti-guinea pig FITC conjugate (Dako) and Alexafluor 568 conjugated anti-rabbit (Molecular Probes).

For immunogold electron microscopy rat pancreas was fixed in cacodylate-buffered $4 \%$ paraformaldehyde $/ 0.5 \%$ glutaraldehyde and embedded in LR-white. Ultra-thin sections on nickel formvar coated grids were blocked with $0.1 \%$ fish skin gelatin for $1 \mathrm{~h}$. Primary antibodies were 1:200 dilutions of preimmune or immune anti- 
GHTD-amide rabbit sera and secondary antibody was 1:80 dilution of goat anti-rabbit conjugated to $10 \mathrm{~nm}$ gold (Aurion, Costerwegs, The Netherlands). Sections were stained with lead citrate before visualization by transmission electron microscopy. Gold particles decorating the dense core and halo of secretory granules were counted on 5 randomly selected beta cells from preimmune and immune serum incubations of each of 2 rat pancreases.

\subsection{Statistics}

Statistical analysis of data used GraphPad Prism software. Student's $t$-test was used for between group comparisons and group sizes and $p$ values are as described in the figure legends. Animal data were baseline corrected and analyzed by Student's $t$-test.

\section{Results}

\subsection{Purification and sequencing of the urinary peptide}

The active constituent was purified from semi-purified urine extracts using a four-step reverse-phase HPLC procedure employing Vydac C18 and C3 columns with bioactivity confirmed at each step by assay of stimulation of glycogen synthesis in rat hemidiaphragm. ES mass spectrometry identified a single charged molecular ion species $\left(\mathrm{M}+\mathrm{H}^{+}\right)$with a $\mathrm{m} / z$ ratio of $429 \mathrm{Da}$. Amino acid sequencing and ES-MS/MS fragmentation identified an alphaamidated tetrapeptide Gly-His-Thr-Asp.

\subsection{Effects of GHTD-amide on glycogen synthesis}

The tetrapeptide GHTD-amide was synthesized and tested for stimulation of glycogen synthesis in HepG2 cells and C2C12 myotubes. In HepG2 cells the peptide significantly increased D[U- $\left.{ }^{14} \mathrm{C}\right]$-glucose incorporation into glycogen at concentrations ranging from $1 \mathrm{pM}$ to $1 \mathrm{nM}$ to levels similar to that induced by $10 \mathrm{nM}$ insulin (Fig. 1A). At a concentration of 100 pM GHTD-amide was more potent than $1 \mathrm{nM}$ insulin $(p<0.05)$. Evidence of high dose inhibition was apparent with $10 \mathrm{nM}$ GHTD-amide showing significantly reduced activity compared to the optimally active concentration of $100 \mathrm{pM}$ GHTD-amide $(p=0.05)$.

In C2C12 myotubes GHTD-amide stimulated glycogen synthesis but to a lesser degree and with lower potency than in HepG2 cells. D$\left[\mathrm{U}-{ }^{14} \mathrm{C}\right]$-glucose incorporation into glycogen was significantly greater than basal at concentrations of 1 and $10 \mathrm{nM}(p<0.05)$ but not at 0.1 and $100 \mathrm{nM}(p>0.2)$ (Fig. 1B). Insulin (10 nM) increased glycogen synthesis by $80 \%$ and $117 \%$ in $\mathrm{C} 2 \mathrm{C} 12$ and HepG 2 cells respectively whereas GHTD-amide caused increases of $40 \%$ and $260 \%$ in the respective cell models, further reinforcing the greater potency of the peptide in HepG2 cells. There was no additive effect of GHTD-amide and insulin in C2C12 cells with the combined treatments not significantly different to GHTD-amide alone (Fig. 1B). Addition of GHTD-amide to $10 \mathrm{nM}$ insulin caused an apparent decrease in glycogen synthesis compared to $10 \mathrm{nM}$ insulin alone but this did not reach statistical significance $(p=0.4-0.5)$.

\subsection{Hypoglycemic activity of GHTD-amide in insulin-deficient rats}

Hypoglycemic activity in combination with insulin was tested in insulin-deficient Wistar rats (Fig. 2). This model was chosen to minimize complications due to endogenous insulin secretion. Injection of the rats with streptozotocin successfully ablated insulin production by the pancreatic beta cells as shown by a substantial decrease in serum insulin from (mean $\pm \mathrm{SEM}$ ) $2.2 \pm 0.6 \mathrm{ng} / \mathrm{ml}$ prior to stz treatment to $0.28 \pm 0.08$ after treatment. Fasting blood glucose prior to insulin tolerance tests were $16.5 \pm 1.7$ and $17.3 \pm 1.4 \mathrm{mM}$ for insulin and insulin plus GHTD-amide
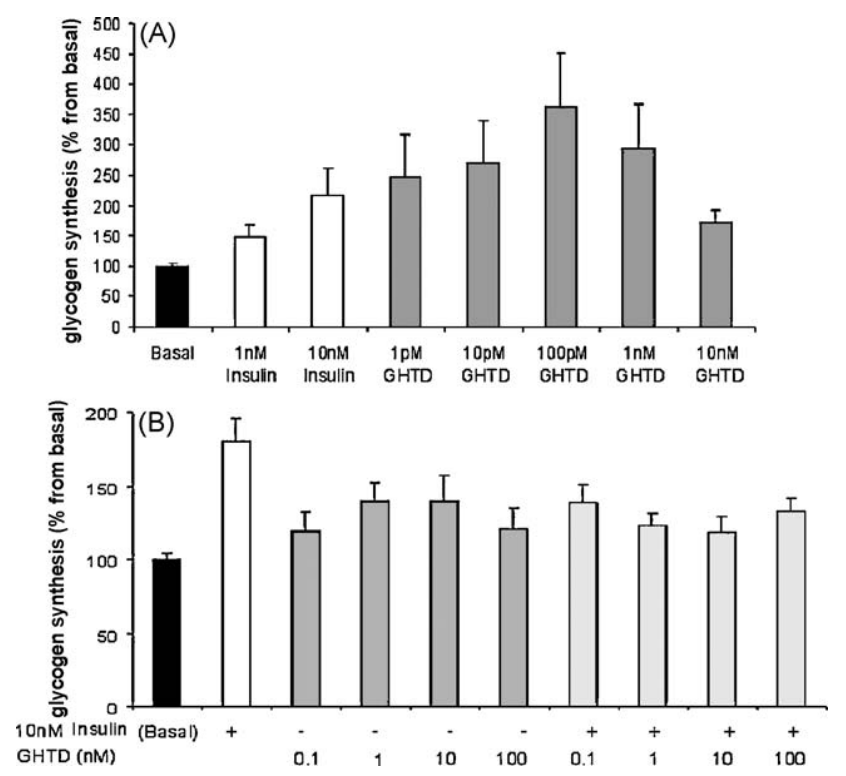

Fig. 1. Synthetic GHTD-amide promotes glycogen synthesis and enhances insulinmediated glucose lowering activity. (A) Glycogen synthesis in HepG2 cells incubated with 1 or $10 \mathrm{nM}$ insulin (white bars), $1 \mathrm{pM}$ to $10 \mathrm{nM}$ GHTD-amide (grey bars) or control (black bar). Both insulin and GHTD-amide significantly increased $\mathrm{D}-\left[\mathrm{U}-{ }^{14} \mathrm{C}\right]$ glucose incorporation into glycogen compared to basal ( $p<0.05$ for each treatment compared to basal, Student's $t$-test), $n=9$ for each treatment and standard errors are shown by bars. (B) Glycogen synthesis in C2C12 myotubes incubated with $10 \mathrm{nM}$ insulin (white bars), 0.1-100 nM GHTD-amide (grey bars), $10 \mathrm{nM}$ insulin with 0.1-100 nM GHTD-amide (light grey bars) or control (black bar). Both insulin and GHTD-amide at 1 and $10 \mathrm{nM}$ significantly increased D$\left[\mathrm{U}-{ }^{14} \mathrm{C}\right]$ glucose incorporation into glycogen compared to basal $(p<0.05$ for each treatment compared to basal, Student's $t$-test), $n=9$ for each treatment and standard errors are shown by bars.

respectively. Injection of the rats with $1 \mathrm{U} / \mathrm{kg}$ insulin caused a significant reduction in blood glucose with the largest average decrease of $8.3 \mathrm{mM}$ occurring after $90 \mathrm{~min}$ (Fig. 2). When GHTDamide was combined with the insulin injection blood glucose decreased by $11.1 \mathrm{mM}$ after $90 \mathrm{~min}$ and was lower than for the insulin treatment throughout the time-course.

\subsection{Immunochemical localization of GHTD-amide peptide}

A rabbit anti-serum was raised to the amidated carboxylterminus of synthetic GHTD-amide conjugated to diphtheria

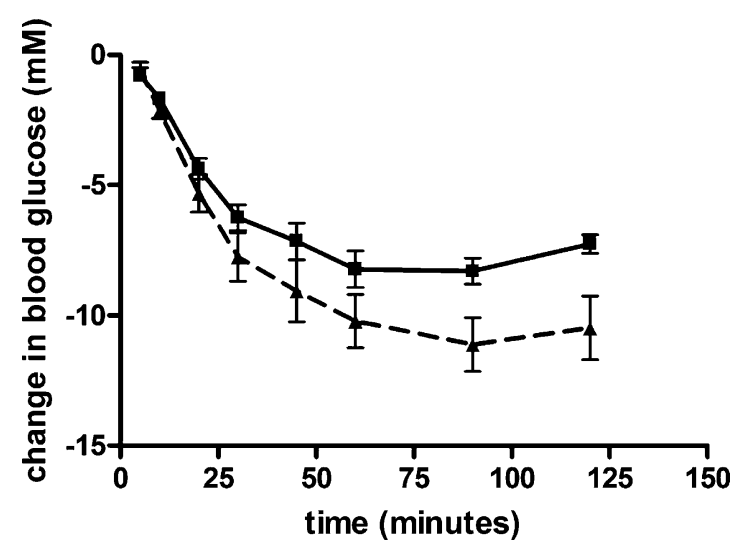

Fig. 2. Reductions in blood glucose after injection of insulin or insulin and GHTDamide. Insulin-deficient male Wistar rats $(n=7)$ were injected with insulin at $1 \mathrm{U} /$ $\mathrm{kg}$ (solid line) or insulin with $4.27 \mathrm{mg} / \mathrm{kg}$ GHTD-amide in a cross-over study and blood glucose measured at regular intervals for $2 \mathrm{~h}$. The difference in blood glucose between treatments was significant at 90 and $120 \mathrm{~min}(p<0.05$, Student's $t$-test). 


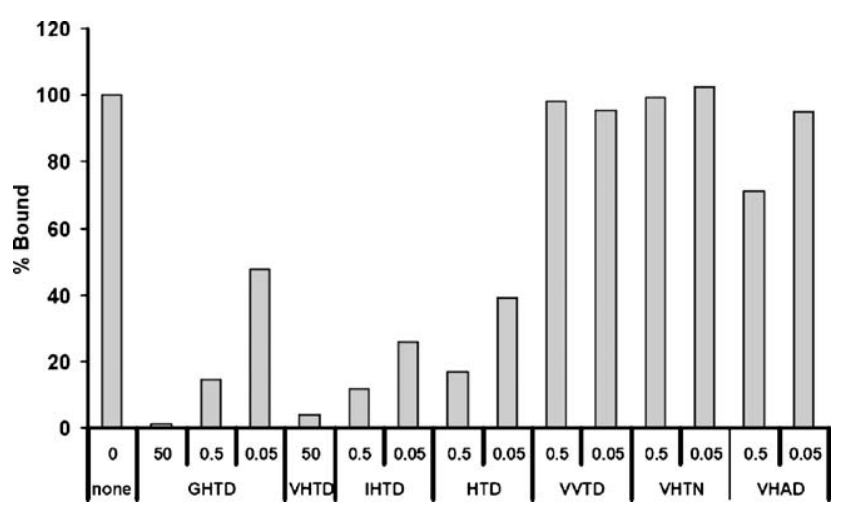

Fig. 3. The rabbit anti-serum raised to GHTD-amide recognizes the HTD-amide sequence. Radio-immunoprecipitation of ${ }^{125}$ I-YGHTD was performed using a rabbit anti-serum raised to diphtheria toxoid-conjugated GSGSGHTD-amide. Competition with various peptides was performed at the concentrations shown (in microgram per $\mathrm{ml}$ ). All competing peptides are alpha-amidated. The His, Thr and amidated Asp all contribute to the epitope. toxoid. The specificity of the rabbit anti-serum was tested using an iodinated variant of the peptide, ${ }^{125}$ iodo-YGHTD-amide, and competition for binding to the anti-GHTD-amide serum by tetrapeptide sequence variants of GHTD-amide (Fig. 3). All peptides containing HTD-amide effectively competed with ${ }^{125}$ iodo-YGHTD-amide for binding to the anti-serum regardless of the amino acid in the first position. Substitution of His with Val, Asp with Asn or Thr with Ala each eliminated or significantly reduced competition, indicating that all three residues are required to form the epitope (Fig. 2). These results identify the epitope recognized by anti-GHTD-amide as HTD.

A range of tissues were screened by indirect immunofluorescence using anti-GHTD-amide including pancreas, liver, muscle, kidney and adipose tissue from mouse and the endocrine glands, adrenal, maxillary, thyroid (fetal), brain (pituitary gland), parathyroid and pancreas from human. Indirect immunofluorescence identified staining of pancreatic islets of both mouse and human (Fig. 4B and D). All other tissues showed no staining. In both mouse and human the rabbit anti-serum co-localized with an antibody to insulin (Fig. 4C, E and F), which identifies the GHTD-amide positive cells as pancreatic beta cells. There was no staining of islets apparent with pre-immune serum (not shown). To further confirm beta cell localization, mouse monoclonal antibodies were raised to
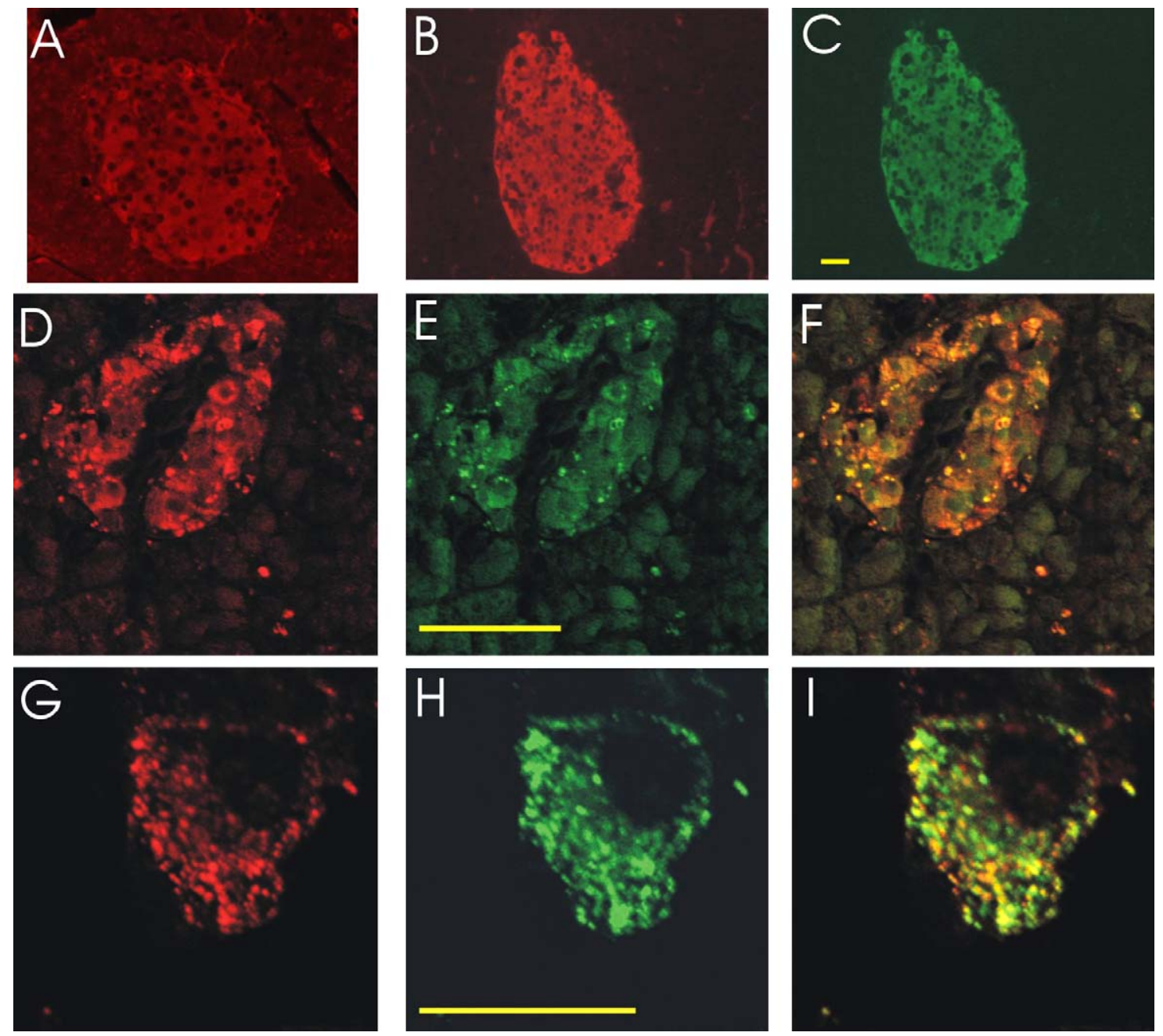

Fig. 4. Antibodies to GHTD-amide decorate pancreatic islets of mouse and human and co-localize with insulin. A mouse monoclonal antibody and rabbit anti-sera were raised to GHTD-amide conjugated to diphtheria toxoid. Tissue sections were stained with the GHTD-amide antibody and/or an anti-insulin antibody raised in guinea pig (Dako) and anti-rabbit or anti-mouse IgG conjugated to Alex568 (Molecular probes) and/or anti-guinea pig IgG conjugated to FITC (Dako). (A) Mouse pancreas stained with a monoclonal antibody that binds to GHTD-amide. (B and C) A mouse pancreatic islet stained with rabbit anti-GHTD-amide (B) and anti-insulin (C). (D-F) Human pancreas showing an islet with a central ductule (Dako) stained with anti-GHTD-amide (D), anti-insulin (E) and an overlay of D and E. (G-I) A single MIN6 mouse islet beta cell stained with anti-GHTDamide $(\mathrm{G})$, anti-insulin $(\mathrm{H})$ and an overlay (I) showing co-localization in cytoplasmic vesicles. Scale bars for (C) and (E) are $50 \mu \mathrm{m}$ and for (H) $25 \mu \mathrm{m}$. 

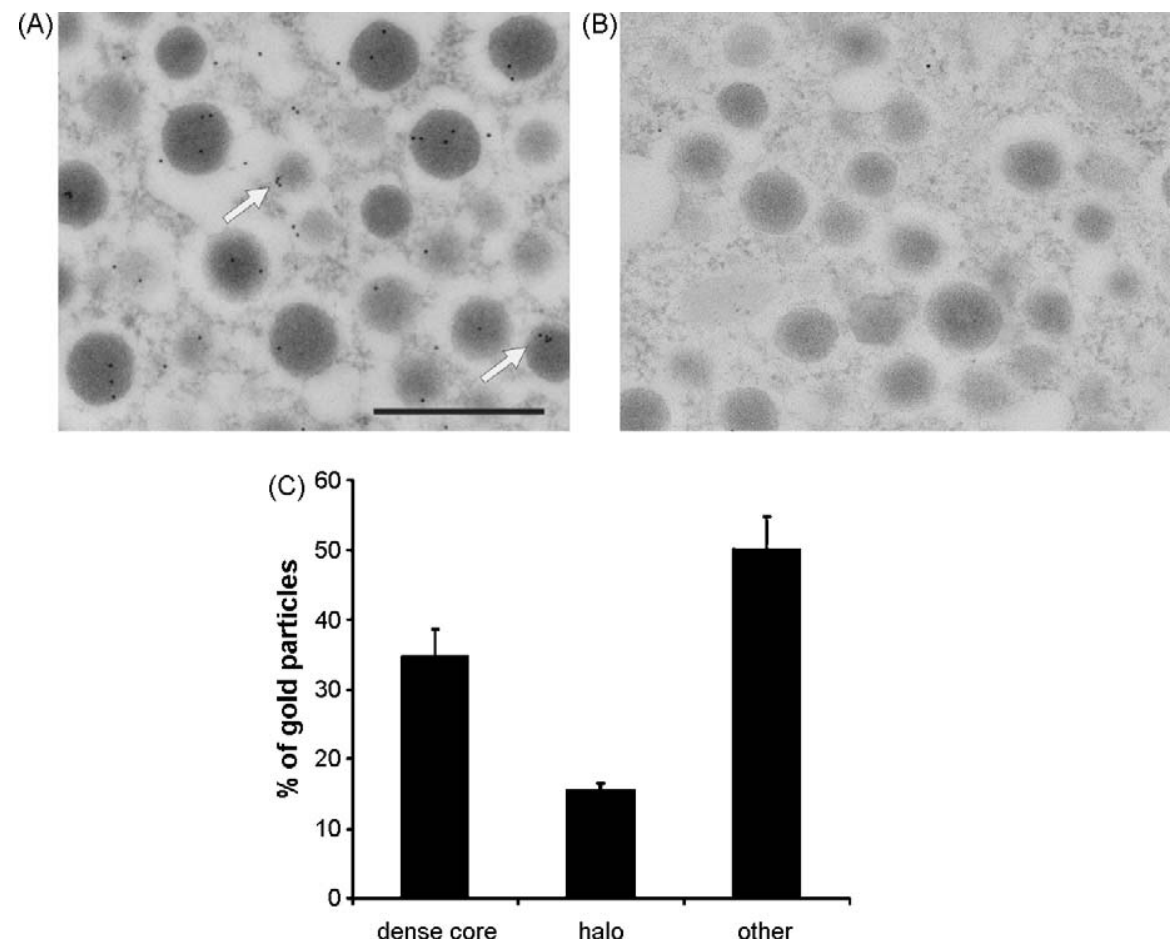

Fig. 5. (A) Electron micrograph showing decoration of secretory granules by $10 \mathrm{~nm}$ gold particles marking binding by the anti-GHTD-amide rabbit anti-serum and (B) sparser numbers of gold particles on a section stained with the pre-immune serum. Magnification $25,000 \times$. Scale bar $0.6 \mu \mathrm{m}$. (C) The number of $10 \mathrm{~nm}$ gold particles decorating the dense core or halo of secretory granules from 10 randomly selected $12.8 \mu \mathrm{m}^{2}$ images. Gold particles that could not be attributed to secretory granules were designated as "other".

the GHTD-amide diphtheria toxoid conjugate. Surprisingly all the monoclonals raised were of the IgM isotype. Supernatant from the best producing clone was used to stain mouse pancreas by indirect immunofluorescence and once again staining was restricted to pancreatic islets (Fig. 4A). The subcellular localization of antiGHTD-amide immunoreactivity in pancreatic beta cells was explored further using the mouse islet beta cell line MIN6. Staining of MIN6 cells with antibodies to insulin and the antiGHTD-amide anti-serum and confocal imaging revealed colocalization of anti-GHTD-amide and insulin binding in the cytoplasm of MIN6 cells (Fig. 4G-I). The overlay shows that while the relative staining intensity with insulin (green) and anti-GHTDamide (red) varies the majority of vesicles in the cytoplasm stained with both antibodies (Fig. 4I).

Immunogold staining for GHTD-amide and electron microscopy was performed on rat pancreas to further define the site of GHTDamide immune reactivity within beta cells. For sections stained with anti-GHTD-amide, there was a significant increase in the density of $10 \mathrm{~nm}$ gold particles decorating dense core secretory granules compared to pre-immune controls (Fig. 5) with an average of $61 \%$ of granules decorated compared to $33 \%$ for the preimmune serum (Fig. 5A and B). Gold particles were distributed throughout the cytoplasm with clusters apparent in the dense core of some secretory granules (Fig. 4A arrowed), whereas preimmune serum showed a lower density and more even distribution of gold particles (Fig. 5B). Counting of gold particles across 10 randomly selected $12.8 \mu \mathrm{m}^{2}$ images showed that $50 \%$ of gold particles were associated with secretory granules divided into $35 \%$ associated with the dense core and 15\% with the halo (Fig. 5C).

\subsection{GHTD-amide in cell culture media conditioned by MIN6 beta cells}

Detection of antigenic structures reactive with the GHTD-amide anti-serum in secretory granules of pancreatic beta cells suggested an islet beta cell origin for urinary GHTD-amide. This was tested using the mouse beta cell line MIN6. Serum free media was conditioned by confluent MIN6 cells for $24 \mathrm{~h}$. Media was collected and concentrated and analyzed for GHTD-amide by HPLC and mass spectrometry. A peptide species that absorbed at $214 \mathrm{~nm}$ with a retention time on C18 reverse phase HPLC (16.2 min) equivalent to that of synthetic GHTD-amide was identified in conditioned media but was absent in unconditioned media (Fig. 6). MALDI-TOF mass spectrometry on the 16-17 min fraction revealed a peptide species with average molecular weight of $429 \mathrm{Da}$ and $\mathrm{ms} / \mathrm{ms}$ produced fragment sizes consistent with GHTD-amide as assigned by the ion

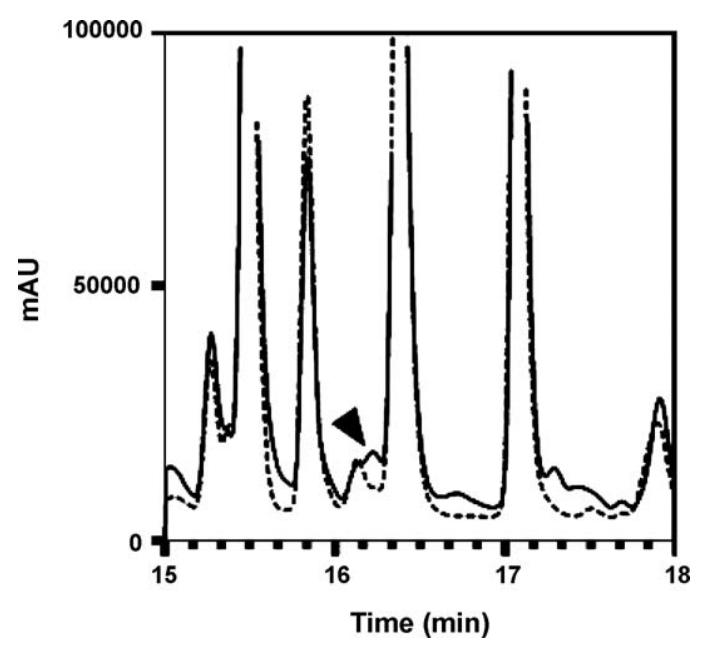

Fig. 6. GHTD-amide is secreted by MIN6 cells. Serum free media conditioned for $24 \mathrm{~h}$ by a confluent layer of MIN6 cells was separated by reverse phase HPLC. Absorption at $214 \mathrm{~nm}$ for the conditioned media (solid line) and unconditioned serum free media (dashed line) identified the appearance of several peaks in conditioned media, including a species with a retention time equivalent to synthetic GHTD-amide (16.2 min, arrowed). This species was identified as GHTDamide by MALDI-TOF mass spectrometry. 
Table 1

MALDI-TOF fragmentation of GHTD-amide from media conditioned by MIN6 cells.

\begin{tabular}{|c|c|c|c|c|c|c|c|c|}
\hline \multirow{2}{*}{$\begin{array}{l}\text { Mass (Da) } \\
\text { Assignment }\end{array}$} & 429 & 385 & 269.9 & 251.9 & 241.0 & 196.0 & 169.0 & 100.1 \\
\hline & Parent molecule & $\mathrm{m}-\mathrm{T} 1, \mathrm{a} 4$ & a3 & $\mathrm{d} 3 \mathrm{~b}$ & HT & b2 & $\mathrm{a} 2$ & $\mathrm{~d} 2 \mathrm{a}$ \\
\hline
\end{tabular}

fragmentation tool of the GPS explorer software (Table 1). Thus GHTD-amide is produced by MIN6 beta cells confirming pancreatic islet beta cells as an endogenous source of the peptide.

\subsection{A potential precursor of GHTD-amide is not in the annotated human proteome}

A bioinformatics search was performed in an attempt to identify a precursor protein for GHTD-amide. The precursors of all known amidated peptides and proteins contain a Gly adjacent to the C-terminal amidated amino acid [12] and this is generally flanked by a basic residue that serves as a protease cleavage site. Alternatively, the amidated sequence may occur at the C-terminus of the precursor protein with a Gly as the last amino acid. Hence, the sequence GHTDG was used to BLAST search the NCBI nonredundant human protein sequence databases and Swissprot, which contain all characterized and predicted proteins from the human genome. Five proteins were identified that contain the sequence GHTDG. The first 4 of these proteins are members of an evolutionary conserved family of transducin-like enhancer of split transcriptional repressors (TLE1 through to TLE4) that contain WD domains characterized by a GH dipeptide followed 11-24 amino acids later by WD [5]. The GHTDG sequence occurs in a conserved WD domain in this TLE protein family. The other protein is transforming acidic coiled coil containing protein 2 (TACC2) [16]. These proteins are all widely expressed, restricted to the cell nucleus and lack potential protease cleavage sites adjacent to the C-terminal of the GHTDG sequence. There is a higher than expected chance of the GHTDG sequence occurring in these proteins due to the presence of several GH dipeptide motifs in TLE proteins and the high content of Gly (8.8\%) and acidic residues, including Asp (5.5\%), in TACC2. No other GHTDG containing proteins were found in the annotated human proteome.

\section{Discussion}

More than 30 years ago a peptide with insulin potentiating activity was isolated from human urine $[19,20]$ but the technology to identify the peptide was not then available. Here we have shown that the active constituent is a tetrapeptide with the sequence GHTD-amide. Synthetic GHTD-amide stimulated glycogen synthesis in a hepatoma cell line and $\mathrm{C} 2 \mathrm{C} 12$ myotubes and enhanced insulin-mediated glucose lowering in an insulin-deficient rat model of diabetes confirming that GHTD-amide is the active molecule originally described in human urine.

The original purification of the urinary peptide found the peptide to only be active in the presence of insulin [19,20,32]. In this study activation of glycogen synthesis in liver and muscle cell lines in the absence of insulin identifies an insulin-like activity attributable to GHTD-amide. This activity showed a high-dose inhibition effect, with reduced activity at concentrations above $100 \mathrm{pM}$ in HepG2 cells. Reduced cellular responses at high concentrations are also frequently observed for insulin due to negative co-operativity in binding to the insulin receptor [9]. This may suggest that GHTD-amide is also operating through a receptor but as yet this has not been identified. Hypoglycemic activity in an insulin-deficient animal model may therefore be attributable to direct actions of the peptide or to the insulin potentiating activity originally described for the peptide preparations from urine.
Alpha-amidation of the carboxyl terminal amino acid is common in secreted peptide hormones, growth factors and neuropeptides [12]. However, alpha amidated aspartic acid appears to be uncommon with the only example being an opioid peptide from frog skin called deltorphin or dermenkephalin $[2,23]$. To our knowledge GHTD-amide is the first mammalian derived peptide described that contains alpha-amidated aspartic acid.

The rabbit anti-serum raised to a diphtheria toxoid/GHTDamide conjugate bound to pancreatic islets and no other tissues. The specificity of the anti-serum for the C-terminus of the peptide, the unique nature of amidated Asp at the C-terminus, and the demonstration that MIN6 cells release GHTD-amide into cell culture media suggest that pancreatic beta cells are an endogenous source of this peptide. At this stage it is unclear whether GHTD-amide is co-secreted with insulin in response to glucose and amino acid stimuli since the detection methods currently available lack sufficient sensitivity to perform these experiments and the quantities released from MIN6 cells are small. A search for circulating endogenous GHTD-amide using the radioimmunoassay described here and a LC/MS/MS bioanalytical method both failed to detect the peptide in human or rodent plasma (data not shown) indicating that, if the peptide is present in the circulation, concentrations are below the lower limit of detection $(0.5 \mathrm{ng} / \mathrm{ml})$ of these methods. Co-localization with insulin in secretory granules of MIN6 cells and immunogold staining of dense core secretory granules suggest that further investigation of how GHTD-amide is released from MIN6 beta cells is warranted.

Peptides in urine usually derive from fragmented circulating plasma proteins and bioactive peptides [7]. It would be anticipated that GHTD-amide, like other alpha-amidated peptides, is processed from a larger precursor protein and released into the circulation, but no protein fulfilling the criteria for a precursor is present in the annotated human proteome. A precedent for endogenous alpha amidated tetrapeptides for which a precursor protein is not known is the endomorphins. Endomorphins were first isolated from brain and bind with high affinity and selectivity to mu opioid receptors [22,31]. A search for precursor proteins for endomorphin-1 (Tyr-Pro-Trp-Phe-amide) and endomorphin-2 (Tyr-Pro-Phe-Phe-amide) found no evidence of such proteins in the human proteome [30] and it has even been suggested that they may be synthesized non-ribosomally [24]. Many peptide hormone precursors are short polypeptides encoded by small messenger RNA that can be underrepresented in cDNA libraries and easily overlooked by gene prediction algorithms. There has been some success in identifying novel peptide hormone/neuropeptideencoding genes using more complex algorithms and hidden Markov models [3,18]. However, these approaches are not guaranteed of success since the conserved bioactive regions encoded by some neuropeptide genes are interrupted by introns, as is seen in the neuropeptide $Y$ family where the encoded RQRYamide motif contains an intron in the codon for the penultimate residue in the RQRY peptide sequence $[15,17]$. Hence, it is possible that genes encoding precursor proteins for GHTD-amide and endomorphins exist but as yet have not been detected due to their small size or interruption of the encoded tetrapeptide sequences by introns. Resolution of this problem will require either purification of the unprocessed precursor proteins, extensive expression screening of small and rare cDNA clones from source tissues or a clear demonstration of non-ribosomal synthesis. 
In conclusion, GHTD-amide is a novel islet beta cell peptide that stimulates glycogen synthesis in muscle and liver cells and enhances insulin-mediated blood glucose lowering in an insulindeficient animal model of diabetes. While the mode of biosynthesis of the peptide remains unknown this activity and its production by pancreatic beta cells suggest a role in normal glucose homeostasis. Further study of the physiological role of GHTD-amide in health and disease will provide further insights into the regulation of blood glucose.

\section{Acknowledgements}

We thank the Monash Biomedical Proteomics facility for help. This work was supported by Dia-B Tech Limited.

\section{References}

[1] Ahrén B, Pacini G, Wynick D, Wierup N, Sundler F. Loss-of-function mutation of the galanin gene is associated with perturbed islet function in mice. Endocrinology 2004;145:3190-6.

[2] Amiche M, Sagan S, Mor A, Delfour A, Nicolas P. Dermenkephalin (Tyr-o-MetPhe-His-Leu-Met-Asp-NH2): a potent and fully specific agonist for the delta opioid receptor. Mol Pharmacol 1989;35:774-9.

[3] Baggerman G, Liu F, Wets G, Schoofs L. Bioinformatic analysis of peptide precursor proteins. Ann NY Acad Sci 2005;1040:59-65.

[4] Buchanan CM, Phillips ARJ, Cooper GJS. Preptin derived from proinsulin-like growth factor II (proIGF-II) is secreted from pancreatic islet b-cells and enhances insulin secretion. Biochem J 2001;360:431-9.

[5] Chen G, Courey AJ. Groucho/TLE family proteins and transcriptional repression. Gene 2000;249:1-16.

[6] Cooper G. Amylin compared with calcitonin gene-related peptide: structure, biology, and relevance to metabolic disease. Endocr Rev 1994;15:163-201.

[7] Cutillas PR, Norden AGW, Cramer R, Burlingame AL, Unwin RJ. Detection and analysis of urinary peptides by on-line liquid chromatography and mass spectrometry: application to patients with renal Fanconi syndrome. Clin Sci 2003;104:483-90.

[8] Date Y, Nakazato M, Hashiguchi S, Dezaki K, Mondal MS, Hosoda H, et al. Ghrelin is present in pancreatic $\alpha$-cells of humans and rats and stimulates insulin secretion. Diabetes 2002;51:124-9.

[9] De Meyts P, Roth J, Neville Gavin JRIII J, Lesniak MA. Insulin interactions with its receptors: experimental evidence for negative cooperativity. Biochem Biophys Res Commun 1973;55:154-61.

[10] Dezaki K, Sone H, Yada T. Ghrelin is a physiological regulator of insulin release in pancreatic islets and glucose homeostasis. Pharmacol Therap 2008;118: 239-49.

[11] Efendić S, Tatemoto K, Mutt V, Quan C, Chang D, Ostenson CG. Pancreastatin and islet hormone release. Proc Natl Acad Sci USA 1987:84:7257-60.

[12] Eipper BA, Stoffers DA, Mains RE. The biosynthesis of neuropeptides: peptide $\alpha$-amidation. Annu Rev Neurosci 1992;15:57-85.
[13] Hettiarachchi M, Chalkley S, Furler SM, Choong YS, Heller M, Cooper GJ, et al. Rat amylin-(8-37) enhances insulin action and alters lipid metabolism in normal and insulin-resistant rats. Am J Physiol 1997;273:E859-67.

[14] Huang D, Cheung AT, Parsons JT, Bryer-Ash M. Focal adhesion kinase (FAK) regulates insulin-stimulated glycogen synthesis in hepatocytes. J Biol Chem 2002;277:18151-60.

[15] Larhammar D, Ericsson A, Persson H. Structure and expression of the rat neuropeptide Y gene (gene famfly/polymorphism/mRNA). Proc Natl Acad Sci USA 1987;84:2068-72.

[16] Lauffart B, Gangisetty O, Still IH. Molecular cloning, genomic structure and interactions of the putative breast tumor suppressor TACC2. Genomics 2003:81:192-201.

[17] Minth CD, Bloomt SR, Polakt JM, Dixon JE. Cloning, characterization, and DNA sequence of a human cDNA encoding neuropeptide tyrosine. Proc Natl Acad Sci USA 1984;81:4577-81.

[18] Mirabeau O, Perlas E, Severini C, Audero E, Gascuel O, Possenti R, et al. Identification of novel peptide hormones in the human proteome by hidden Markov model screening. Genome Res 2007;17:320-7.

[19] Ng FM, Zimmet P, Bornstein J, Malinek M, Taft P. Isolation and characterization of a hypoglycaemic peptide from human urine. Proc Endocr Soc Aust 1971;14:51.

[20] Ng FM, Zimmet PZ, Seiler G, Taft P, Bornstein J. Insulin potentiating action of a peptide fraction from urine. Diabetes 1974;23:950-6.

[21] Ohtaki T, Shintani Y, Honda S, Matsumoto H, Hori A, Kanehashi K, et al. Metastasis suppressor gene KiSS-1 encodes peptide ligand of a G-proteincoupled receptor. Nature 2001;411:613-7.

[22] Pan W, Kastin AJ. From MIF-1 to endomorphin: the Tyr-MIF-1 family of peptides. Peptides 2007;28:2411-34

[23] Richter K, Egger R, Kreil G. D-Alanine in the frog skin peptide dermorphin is derived from L-alanine in the precursor. Science 1987;238:200-2.

[24] Ronai AZ, Szemenyei E, Kato E, Kocsis L, Orosz G, Al-Khrasani M, et al. Endomorphin synthesis in rat brain from intracerebroventricularly injected [3H]-Tyr-Pro: a possible biosynthetic route for endomorphins. Regul Peptides 2006; 134:54-60.

[25] Rushing PA, Hagan MM, Seeley RJ, Lutz TA, Woods SC. Amylin a novel action in the brain to reduce body weight. Endocrinology 2000;141:850-3.

[26] Sanchez-Margalet V, Lucas M, Goberna R. Pancreastatin: further evidence for its consideration as a regulatory peptide. J Mol Endocrinol 1996;16:1-8.

[27] Silvestre RA, Egido EM, Hernández R, Marco J. Kisspeptin-13 inhibits insulin secretion without affecting glucagon or somatostatin release: study in the perfused rat pancreas. J Endocrinol 2008;196:283-90.

[28] Silvestre RA, Miralles P, Monge L, Moreno P, Villanueva ML, Marco J. Effects of galanin on hormone secretion from the in situ perfused rat pancreas and on glucose production in rat hepatocytes in vitro. Endocrinology 1987;121:37883.

[29] Tatemoto K, Efendić S, Mutt V, Makk G, Feistner GJ, Barchas JD. Pancreastatin, a novel pancreatic peptide that inhibits insulin-secretion. Nature 1986;324: $476-8$

[30] Terskiy A, Wannemacher KM, Yadav PM, Tsai M, Tian B, Howells RD. Search of the human proteome for endomorphin-1 and endomorphin-2 precursor proteins. Life Sci 2007;81:1593-601.

[31] Zadina JE, Hackler L, Ge LJ, Kastin AJ. A potent and selective endogenous agonist for the mu-opiate receptor. Nature 1997;386:499-502.

[32] Zimmet P, Ng F, Bornstein J, Taft P. Somantin(In-G), cataglycin (Ac-G) and glucose homeostasis in man. Horm Metab Res 1972;4:309-10. 